\title{
A GIS tool for the design and assessment of road drain spacing to minimize stream pollution: RoadCAT
}

\author{
$\underline{\text { C.J. Thompson }}{ }^{\text {a }}$, A. Hicks ${ }^{\text {a }}$ and X. Sun ${ }^{\text {a }}$ \\ ${ }^{a}$ Integrated Catchment Assessment and Management (iCAM) Centre, The Fenner School of Environment and \\ Society, The Australian National University, Australian Capital Territory \\ Email: christopher.thompson@anu.edu.au
}

\begin{abstract}
Unsealed roads are an important source of runoff and sediment which can affect the hydrology and water quality of streams. The Road Connectivity Assessment Tool (RoadCAT) is being developed based on the conceptual framework of volume-to-breakthrough and hydrological connectivity between roads and streams in managed forest environments that allows identification of the different types of delivery pathways and estimation of the runoff volumes delivered through them. RoadCAT is built in ArcGIS's model builder using existing and customised toolboxes. RoadCAT uses rainfall event intensity data, a digital elevation model, roads vector layer and drain points layer (if assessing existing drains) to model drains likely to cause gully erosion at drain outlet, drains connecting with adjacent streams, volume of runoff likely to connect and quantity of suspended sediment potentially transported to the stream based on empirical event-based models. This paper reports on the development of the RoadCAT tool and its application to a South Australian Water Corporation reserve in which new roads are being constructed for reserve management and fire fighting access, and the opportunity presented to model an unconstrained drain spacing design to prevent gully erosion at drain outlets and minimise road runoff connectivity to reduce stream pollution with suspended sediment.
\end{abstract}

Keywords: Geographical Information System (GIS), model builder, road runoff, erosion, water quality, 


\section{INTRODUCTION}

Unsealed roads are important infrastructure in rural and regional Australia for linking people, for agriculture production and forest managment. They are linear features in the landscape that intersect, concentrate and redirect flow paths which can alter catchment hydrology (Wemple et al., 2001). Runoff from unsealed roads can carry high sediment loads (eg. Reid and Dunne, 1984; Croker et al., 1993) and are now recognized as one of the dominant sources of sediment delivered to streams (Richardson, 1985; Takken et al., 2008). Sediment loads generated from unsealed roads depend on traffic use, rainfall (total and intensity), road slope, soil type and time since previous rainfall (Fu et al., 2010; Ramos-Scharron, 2007; Sheridan and Noske, 2007). Sediment loads are also generated from the hillslope if the velocity of the runoff plume is sufficient to entrain surface soil. Road runoff and eroded sediment can enter the stream at road-stream crossings, via gullies at drain outlets that concentrate the flow all or part of the way to the stream, and via diffuse overland flow.

A decision support system is being built in ArcGIS's model builder using existing and customised toolboxes. This road runoff and sediment connectivity assessment tool (RoadCAT) uses rainfall event intensity data, a digital elevation model, roads vector layer and drain points layer (if assessing existing drains) to model drains likely to:

1. directly connect runoff at road-stream crossings,

2. cause gully erosion at drain outlet,

3. connect with adjacent streams via concentrated flow,

4. connect with adjacent streams via diffuse overland flow,

5. volume of runoff likely to connect, and

6. the quantity of suspended sediment potentially transported to the stream.

The prediction of gully erosion at the drain outlet is based on the erosion threshold models of Montgomery (1994) and Montgomery and Dietrich (1988) which have been revised for southeast Australia by Croke and Mockler (2001). The model is based on a relationship between the road runoff contributing area (Fig.1) and the hillslope gradient at the drain outlet.

Diffuse overland flow travel distance is based on a probabilistic model developed by Hairsine et al. (2002). It uses the concept of the 'volume to breakthrough' (VBT), which is the volume of runoff required to enter an area before discharge is observed at the downslope boundary of that area. The VBT model requires variables of i) distance of drain outlet from the stream, ii) road contributing area (or road length), iii) road infiltration rate and iv) a designer rainfall event to calculate runoff volume. The VBT concept has been applied to a number of forest roads to assess the adequacy of drains and the degree of road-stream connectivity (Takken et al., 2006, 2008). Given VBT is an empirical model for diffuse overland flow, field pumping experiments have been conducted across a wide range of bioregions in southeast Australia including southeast NSW (Hairsine et al., 2002; Thompson unpublished data), northeast Victoria (Sheridan et al., 2006), Cotter Catchment, ACT (Thompson et al., 2008) and Northeast NSW (Thompson unpublished data).

RoadCAT can be used to determine the location of "additional drains" where the existing drain configuration is inadequate, resulting in high loads of runoff and sediment connecting and polluting streams. The basic concept is when drains are close to streams, road contributing area needs to be small; likewise, when drains are far from streams, road contributing area can be large so long as the gully erosion threshold is not exceeded. The distance between roads and streams are variable, even for a road following a stream. 
Therefore drain locations should be placed in locations to maximize the potential drain outlet distance from the stream, hence maximizing the distance between drains and therefore reducing the total number of (additional) drains required. Secondly, if it is economically and physically unrealistic to stop all road runoff from connecting with streams, RoadCAT can be used to target the most significant polluting road segments for drainage improvement.

The aim of this paper is to describe RoadCAT and present results from its application to a water reserve catchment in South Australia in which new roads are to be built and the road drainage to be designed to minimize stream pollution from suspended sediment.

\section{THE STUDY AREA}

The study area is located near Clarendon in the hinterland of Adelaide, South Australia. The study area, with undulating topography dissected by a number of first and second order channels, has previously been used for cattle grazing (Fig. 2). The South Australian Water Corporation is now managing the reserve and wants to add $5.4 \mathrm{~km}$ of unsealed road for managing the 450 hectare reserve. The road alignment roughly follows old vehicle tracks and includes four stream crossings. The rainfall intensity for a 10 year average return interval storm of 30 minutes duration is $41.4 \mathrm{~mm} / \mathrm{hr}$.

\section{ROADCAT}

RoadCAT is a decision support system (DSS) that combines several models of runoff and sediment delivery with significant spatial and empirically-based data inputs. The conceptualisation is based on current scientific understanding of the underlying processes of road-stream connectivity. The spatial and empirical data inputs enable tailoring of the model to specific local conditions to enable its widespread application. RoadCAT currently runs on ArcGIS version 9.3 and requires ArcGIS Spatial Analyst and 3D Analyst licenses to perform hydrologic analysis on the DEM for deriving streamlines and hillslope flow paths. Required input data includes a DEM (raster), a road shapefile (polyline) with an attribute table including information on road class/type, a drain shapefile (point), and rainfall intensity for a 10 year average return interval event of 30 minutes duration.

RoadCAT is comprised of seven modules (Fig. 3):

- Catchment hydrology,

- Road setup,

- Road analysis,

- Runoff model,

- Parameter selection module,

- Diffuse flow model,

- Sediment yield model.

The catchment hydrology module utilises existing ArcGIS Spatial Analyst toolbox models for delineating a stream network from a DEM and sets a threshold area for stream starting point based on user input.

The Road setup module clips the vector data to the DEM extent and converts road layer into a 3 dimensional or z-aware layer for splitting

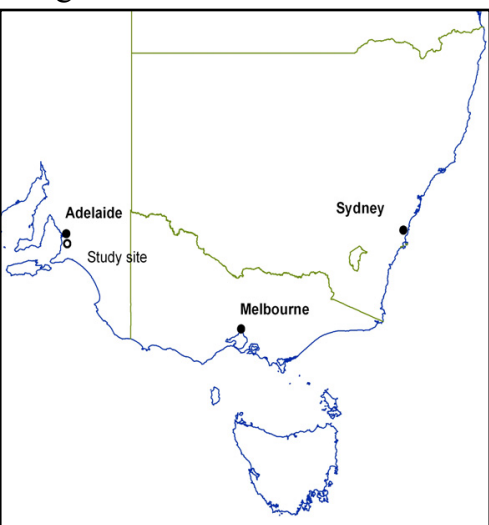

Figure 2. Map of Southeast Australia showing the location of the study site near Adelaide. the road network (at crests, drains and stream crossings) into roadsets which comprise the coupled road element(s) and an associated drain element. A road element is defined as the road area above a drain that captures rainfall and delivers the runoff and eroded sediments to the drain outlet.

Road analysis module calculates the attributes of each road set. This includes: road set length, slope, traffic level, surface type (note; width, traffic and surface type are derived from surrogate variables contained in road layer datasets), contributing road area, flow path distance from drain outlet to stream based on path of steepest descent, and gradient of flow path to stream. The contributing road area $\left(A_{\mathrm{r}}\right)$ is estimated as:

$$
A_{r}=L_{r} W_{r}\left(1-P_{d}\right)
$$

where $L_{r}$ is the contributing road length, $W_{r}$ is the road width and $\left(1-P_{d}\right)$ is the proportion of road width contributing runoff to the table drain. 


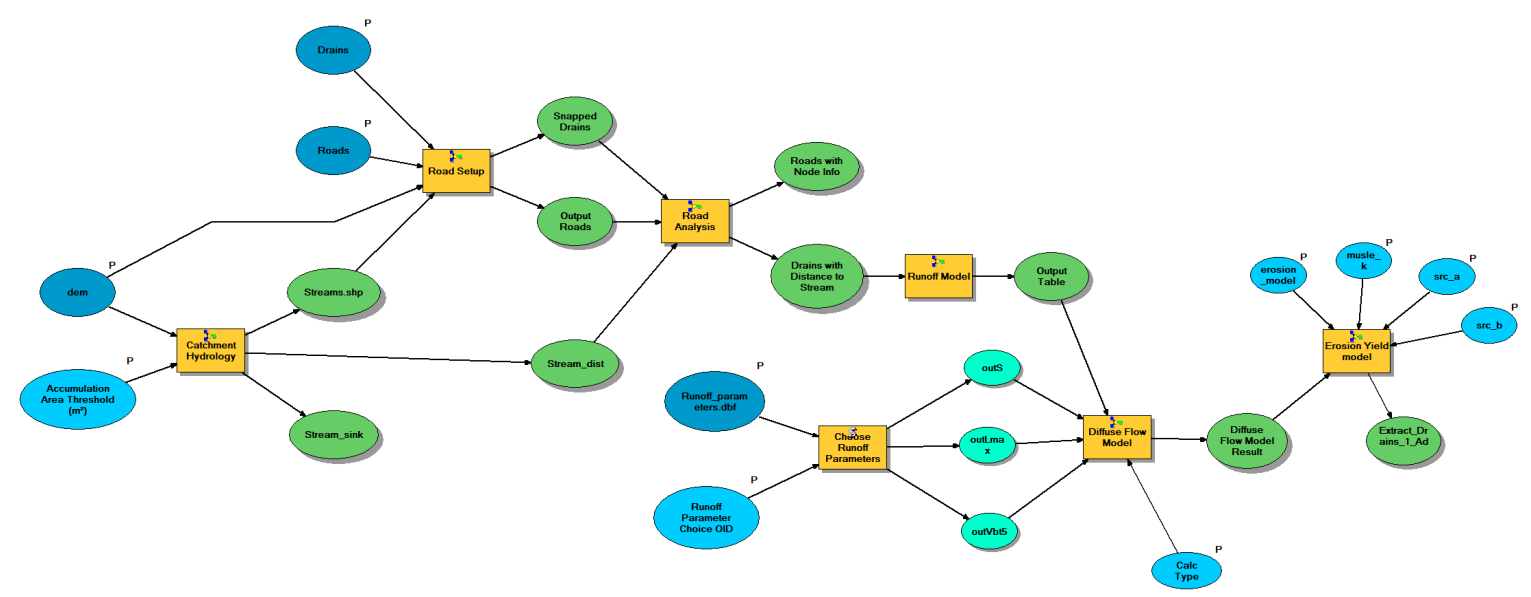

Figure 3. AcrGIS model builder overview of RoadCAT. Rectangle boxes indicate seven different modules comprising RoadCAT, blue ovals indicate input data and green ovals indicate outputs from each module.

Table 1. Parameters derived from field pumping experiments used to set up the diffuse flow module.

\begin{tabular}{|c|c|c|c|c|c|c|c|}
\hline Location & Forest & Disturbance & Flow path & Drain type & Lmax & $\mathbf{S}$ & Vbt5 \\
\hline Cotter, ACT & Dry native & $\begin{array}{l}\text { Intense fire } \\
4 y r s\end{array}$ & $\begin{array}{l}\text { Diffuse and } \\
\text { short rills }\end{array}$ & Pipe & 36.6 & 29717 & 0.105 \\
\hline “ & “ & “ & $\begin{array}{l}\text { Rill full } \\
\text { connection }\end{array}$ & Pipe & 70.7 & 93475 & 0.072 \\
\hline Coffs Harbour & $\begin{array}{l}\text { Wet \& dry } \\
\text { native }\end{array}$ & No recent & Rill/gully & Pipe \& mitre & 58.3 & 179555 & 0.089 \\
\hline “ & “ & “ & Diffuse & Pipe \& mitre & 25.4 & 26873 & 0.185 \\
\hline East Kiewa & Wet native & Burnt & Diffuse & $\mathrm{N} / \mathrm{a}$ & 13.5 & 3690 & No data \\
\hline SE NSW & $\begin{array}{l}\text { Mixed } \\
\text { native }\end{array}$ & No recent & Diffuse & $\begin{array}{l}\text { Rollover } \\
\text { banks }\end{array}$ & No data & No data & 0.347 \\
\hline $\begin{array}{l}\text { Tyers, central } \\
\text { highlands, Vic }\end{array}$ & Wet native & No recent & Diffuse & unknown & 11.4 & 9358 & 0.249 \\
\hline
\end{tabular}

The Runoff model module first uses a simple mass balance approach to calculate the volume of runoff produced from the contributing road area less loss due to infiltration into road surface and table drain $\left(V_{\mathrm{i}}\right)$. The peak discharge is predicted based on the Australian Rainfall and Runoff (2001) temporal pattern hyetographs for 10 year 30 minute duration event $\left(Q_{\mathrm{p}}\right)$ and is calculated as:

$$
Q_{\mathrm{p}}=(0.33 R . t-0.1) L_{\mathrm{r}} W_{\mathrm{r}}\left(1-P_{\mathrm{d}}\right) / 300000\left(\mathrm{~m}^{3} \mathrm{~s}^{-1}\right)
$$

The module then assesses the likelihood of a gully or gully erosion occurring at the drain outlet based on the threshold equation:

$$
A_{\mathrm{r}} \geq A_{\mathrm{t}} / \operatorname{Sin}\left(S_{\mathrm{d}} / \pi .180\right)=\text { gully }
$$

where $S_{\mathrm{d}}=$ hillslope gradient in degrees below drain outlet and $A_{\mathrm{t}}=70 \mathrm{~m}^{2}$

This model becomes a constraint on locating new or additional drains as gully erosion is to be avoided. However, for existing drains, the presence of a gully triggers the selection of parameters for concentrated flow pathways.

The parameter selection module accesses a database of empirical values derived from field pumping experiments. These values are used to parameterize subsequent models based on the characteristics and spatial relationship of the analysis area to the field pumping experiment sites (Table 1).

The diffuse flow module is based on the VBT concept of Hairsine et al. (2002). However, a nonlinear regression model that allows for increasing flow loses down the hillslope is applied. The equation to predict overland flow distance $(D)$ is:

$$
D=L_{\max }\left[1-\exp \left(-V_{\mathrm{i}} /\left(S_{\mathrm{h}} / L_{\max }\right)\right)\right]
$$


where $L_{\max }$ and $S_{\mathrm{h}}$ are fitted parameters. $L_{\max }$ represents the maximum flow distance and $S_{\mathrm{h}}$ correlates with flow loss on the hillslope. To determine the runoff volume connecting with a stream $\left(V_{\mathrm{o}}\right)$ the equation is rearranged to:

$$
V_{\mathrm{o}}=V i-\left(-S_{\mathrm{h}} / L_{\max }\right)\left[\operatorname{Ln}\left(\mid\left(L_{\max }-D_{\mathrm{s}}\right) / L_{\max }\right) \mid\right]
$$

where $V_{\mathrm{i}}=$ runoff volume exiting the drain outlet and $D_{\mathrm{s}}=$ the distance to stream along the flow path. When $V_{\mathrm{o}}=0$ there is no connectivity because all the runoff infiltrates into the hillslope.

The sediment yield module consists of two models; a road erosion model and a hillslope transport model. The road erosion model applies the modified universal soil loss equation (MUSLE) of Williams (1975) who included a runoff erosivity factor to enable the model to be applied to individual storm events. The equation used is:

$$
E_{\mathrm{s}}=11.8\left(V_{\mathrm{i}} Q_{\mathrm{p}}\right)^{0.56} K L S C P
$$

where $\mathrm{K}$ is the soil erodibility factor ( $\mathrm{t}$ ha $\mathrm{h} /$ ha $\mathrm{MJ}^{-1} \mathrm{~mm}^{-1}$ ) and is set to 0.00215 (Sheridan et al., 2006). $L$ is the runoff length factor, $S$ is the runoff slope factor, $C$ is the road surface factor ( $=1$ for gravel roads, $=4$ for native soil roads) and $P$ is the traffic level factor ( $=1$ for low traffic roads, $=2$ for high traffic roads).

$$
\begin{array}{ll}
L=\left(L_{\mathrm{r}} / 22.13\right)^{m} & \text { (Rosewell, 1993) } \\
S=-1.5+6.51 /\left(1+\mathrm{e}^{0.94-5.3 S \mathrm{r}}\right) & \text { (Sheridan et al., 2003) }
\end{array}
$$

where $m=\beta /(1+\beta)$ and $\beta=\left(S_{\mathrm{r}} / 0.0896\right) /\left(3 S_{\mathrm{r}}^{0.8}+0.56\right) . S_{\mathrm{r}}$ is the unit road slope $(\mathrm{m} / \mathrm{m})$.

The hillslope transport model accounts for sediment filtering as a simple decay with distance down the hillslope, and sediment enrichment from the hillslope. The sediment load connecting with the stream $\left(P_{\mathrm{s}}\right)$ in kilograms is given by:

$$
P_{\mathrm{s}}=V_{\mathrm{o}} \cdot\left(E_{\mathrm{s}} / V_{\mathrm{o}}\right)-0.028 D_{\mathrm{s}}+0.48 D_{\mathrm{s}} \cdot V_{\mathrm{e}}
$$

where $V_{\mathrm{e}}$ is the discharge volume at the stream bank enriched by eroded hillslope sediment and set to 60 litres. This value is estimated from field pumping experiments in the Cotter River catchment and is based on initial flow rates of overland flow measured for 1 minute, the time in which the flow remained turbid before returning clear.

New drains can be added manually based on the initial connectivity assessment. Single or multiple new drains can be added and deleted using a GUI and their effect on connectivity assessed. Alternatively, an automated method can be used based on an optimization algorithm as described in Thompson et al. (2009). The automated optimization method is constrained by a minimum distance between drains (10m), the gully erosion threshold which places an upper limit on road length between drains, and the distance to stream.

\section{SENSITIVITY ANALYSIS}

One-at-a-time (OAT) local sensitivity analysis (LSA) was used to evaluate parameter sensitivity at a nominal value of a parameter. To compare the sensitivities of parameters with different units of measure, the sensitivity measure is usually normalised by the reference value at which the derivative is calculated (Campolongo et al., 2000). Typically, the range of variation is taken as identical for all the variables (e.g. 5 $10 \%$ of the nominal values in Newham et al., 2003), and the relative importance of input parameter is thus assessed.

Each parameter was perturbed one at a time by a constant proportion $(90 \%, 95 \%, 105 \%$, and $110 \%)$ of its values whist the rest were fixed. The measure of sensitivity was calculated using the equation:

$$
s_{i}=\frac{\partial y}{\partial \theta_{i}}=\frac{\theta_{i}\left(y_{i}-y_{o}\right)}{\delta \theta_{i} y_{o}}
$$

where $y_{i}$ is the perturbed output; $y_{o}$ is the reference output; $\theta_{i}$ is the parameter value and $\delta \theta_{i}$ is the perturbation of the $i^{t h}$ parameter. The relative change in model outputs indicates the sensitivity of the model to parameter changes (Thornton, 1993). If the output changes drastically, then the model is very sensitive to that parameter. If the model only changes its output slightly (or not at all) when a parameter is changed, the model is considered to be insensitive to that parameter. 
When predicting the volume of runoff, parameters used to model contributing road area $\left(L_{\mathrm{r}}, W_{\mathrm{r}}\right.$ and $\left.P_{\mathrm{d}}\right)$ are most sensitive. While input variable $L_{\mathrm{r}}$ is a sensitive parameter, it is generally constrained by the mapping of drain outlet locations, hence the accuracy in data collection. On the other hand, variables $W_{\mathrm{r}}$ and $P_{\mathrm{d}}$ are difficult to acquire. $W_{\mathrm{r}}$ is generally inferred from road class while $P_{\mathrm{d}}$ is based on the assumption that roads are crowned and therefore drain half the runoff over the fill batter on the outside of the road and the inside half of the road drains to the table drain. Road surveys in the lower Cotter Catchment suggest this is generally the case, but individual road segments between drains can exhibit quite variable road width and $P_{\mathrm{d}}$. The assumption of constant infiltration is thought to be a less important source of error for the study sites due to the generally small effect on runoff contributions compared to the contributing road area. Accordingly, fixing infiltration $(11.7 \mathrm{~mm} / \mathrm{hr})$ may be appropriate, although it is recognized that this value is spatially variable depending on geology, road surfacing material and degree of compaction from traffic. For runoff connectivity prediction, model variable $D_{\mathrm{s}}$ is the next most sensitive parameter to the road contributing

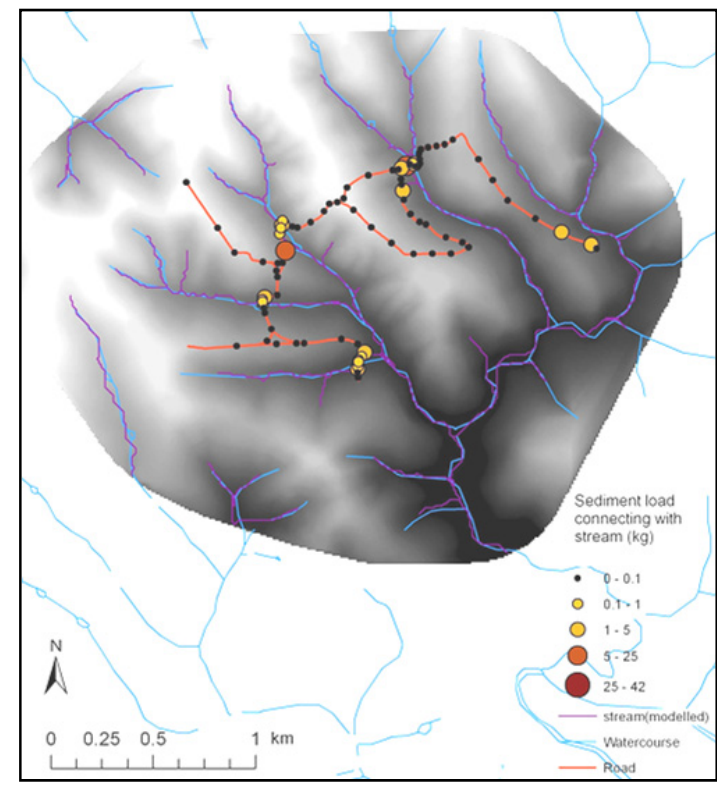

Figure 4. Road drains and predicted suspended sediment loads modelled by RoadCAT for Clarendon water reserve. area variables. Error associated with $D_{\mathrm{s}}$ prediction increases with increasing DEM grid cell size, particularly when grids are $\geq 20 \mathrm{~m}$. Hence, the best method of constraining model error relating to distance to stream prediction is sourcing small grid size DEMs. The OAT method suggests that the parameter-output relationship is sufficiently smooth when the parameter varies only in a small uncertainty range (Chu et al., 2007). Then the assumption that the model output depends on the model parameters in a linear way is valid.

\section{ROADCAT APPLICATION}

The data provided for the Clarendon reserve study site included a 10m DEM and a vector layer of potential new road alignment and a stream layer (Watercourse). Rainfall intensity data was retrieved from the Bureau of Meteorology website: http://www.bom.gov.au/hydro/has/cdirswebx/cdirswebx.shtml. Model default parameters based on the ACT Cotter River catchment field pumping experiments were selected for diffuse overland flow. The catchment hydrology module was run until a drainage network extent similar to the supplied Watercourse layer was achieved (Fig. 4). A result of using a 10m DEM, the alignment of the modeled stream network varied in some locations and influenced the distance to stream variable for a couple of potential drain locations. Drains were added iteratively along the road and successively tested for connectivity and the gully erosion threshold.

Results from the addition of new drains to the road network are presented in Figure 4 using a graduated symbology to illustrate quantity of sediment connecting with the streams based on a 10 year average recurrence interval event of 30 minutes duration. Apart from two drains in the upper northeast corner which require an additional drain to be inserted, the only sediment entering the stream are from drains at the stream crossings. Because there is a minimum distance between drains based on construction requirements, it is not possible to completely stop all sediment entering streams at crossings. To further reduce sediment loads at road-stream crossings, it is recommended that the road should be surfaced by a low sediment yielding material such as coarse gravel or bitumen. In this study site, it may also be possible to realign the road to maximize the entry/exit angles which serves to maximize the flow path distance of the overland flow, hence increase runoff infiltration.

\section{CONCLUSION}

This paper presents an overview of a road runoff and sediment connectivity assessment tool that is implemented in ArcGIS version 9.3, but is untested in version 10. The tool has a modular design which enables straight forward updates in functionality in the future, including the planned upgrade and use of new toolboxes in ArcGIS version 10. Its integration in ArcGIS allows access to the enormous functionality of the platform which can be used for further analysis of the RoadCAT output. We envisage that the application of RoadCAT to road networks, such as forest roads, can identify and assist in directly targeting water pollution source points and lead to improved stream water quality. 


\section{ACKNOWLEDGMENTS}

Thanks to the South Australian Water Corporation for posing the question and supplying the data. Thanks to Peter Manger and Oliver Johns for assisting with code development and funding by ARC project LP0881993.

\section{REFERENCES}

Campolongo, F. Saltelli, A. Sorensen, T. and Tarantola, S. (2000). Hitchhiker's Guide to Sensitivity Analysis. In: Saltelli, A, Chan, K. and Scott, M. (eds) Sensitivity Analysis. John Wiley and Sons, Chichester.

Chu, P.C., Ivanov, LM. and Margolina, TM. (2007). On non-linear sensitivity of marine biological models to parameter variations. Ecological Modelling, 206, 369-392.

Croke, J. and Mockler, S. (2001). Gully initiation and road-to-stream linkage in a forested catchment, southeastern Australia. Earth Surface Processes and Landforms 26, 205-217.

Croker, R. J., Fahey, B. D. and Payne, J. J. (1993). Fine sediment production from truck traffic, Queen Charlotte Forest, Marlborough Sounds, New Zealand. Journal of Hydrology (New Zealand) 31, 56-64.

Fu, B., Newham, T.H., and Ramos-Scharron, C.E. (2010). A review of surface erosion and sediment delivery models for unsealed roads. Environmental Modelling \& Software 25, 1-14.

Hairsine, P. B., Croke, J. C., Mathews, H., Fogarty, P. and Mockler, S. P. (2002). Modelling plumes of overland flow from logging tracks. Hydrological Processes, 16, 2311-2327.

Montgomery, D.R. (1994) Road surface drainage, channel initiation, and slope instability. Water Resources Research, 30, 1925-1932.

Montgomery, DR. and Dietrich, WE. (1988) Where do channels begin? Nature, 336, 232-234.

Newham, LTH. Norton, JP. Prosser, IP. Croke, BFW. and Jakeman, AJ. (2003). Sensitivity analysis for assessing the behaviour of a landscape-based sediment source and transport model. Environmental Modelling and Software 18, 741-751.

Ramos-Scharron, C. E. and MacDonald, L. H. (2007) Runoff and suspended sediment yields from unpaved road segment, St John, US Virgin Islands. Hydrological processes 21, 35-50.

Reid, L. M. and Dunne, T. (1984). Sediment production from forest road surfaces. Water Resources Research 20, 1753-1761.

Richardson, B. A. (1985). The impact of forest road construction on the benthic invertebrate and fish fauna of a coastal stream in southern New South Wales. Australian Society of Limnology Bulletin 10, 65-88.

Rosewell, C.J. (1993). SOILOSS - a program to assist in the selection of management practices to reduce soil erosion. Technical Handbook No.11, Second edition, Soil Conservation Service.

Saltelli, A. (2000). What is Sensitivity Analysis? In: Saltelli, A., Chan, K. AND Scott, M. (eds) Sensitivity Analysis. John Wiley and Sons, Chichester.

Sheridan, G. J. and Noske, P. (2007) A quantitative study of sediment delivery and stream pollution from different forest road types. Hydrological Processes 21, 387-398.

Sheridan, G.J. So, H.B. and Loch R.J. (2003). Improved slope adjustment functions for soil erosion prediction. Australian Journal of Soil Research 41, 1489-1508.

Sheridan, G.J. Noske P.J. Whipp R.K. and Wijesinghe, N. (2006). The effect of truck traffic and road water content on sediment delivery from unpaved forest roads. Hydrological Processes 20, 1683-1699.

Takken, I., Croke, J. and Lane, P. (2008). A methodology to assess the delivery of road runoff in forestry environments. Hydrological Processes, 22, 254-264.

Takken, I., Croke, J. and Mockler, S. (2006). A practical method for the management of road runoff. Sediment Dynamics and the Hydromorphology of fluvial systems (Proceedings of a symposium held in Dundee, UK, July 2006). IAHS Publ. 306, 249-256.

Thompson, C.J. Barry, S. and Takken, I. (2009) A model for optimizing forest road drain spacing. 18th World IMACS / MODSIM Congress, Cairns, Australia 13-17 July 2009. http://mssanz.org.au/modsim09

Thompson, C.J. Takken, I. and Croke, J.C. (2008). Hydrological and sedimentological connectivity of unsealed roads. Sediment Dynamics in Changing Environments (Proceedings of a symposium held in Christchurch, New Zealand, December 2008). IAHS Publ. 325, 2008.

Thornton, K.W. (1993). Sensitivity Analysis and Simulation Experimentation. In: Young, P.C. (ed.) Concise Encyclopedia of Environmental Systems. Pergamon Press, Oxford.

Wemple, B. C., Swanson, F. J. \& Jones, J. A. (2001). Forest roads and geomorphic process interactions, Cascade Range, Oregon. Earth Surface Processes and Landforms 26, 191-204.

Williams, J. R. (1975). Sediment - yield prediction with universal equation using runoff energy factor. Proceedings of the sediment-Yield Workshop, USDA Sedimentation Laboratory, Oxford, Mississippi. 